\title{
Dual Strip-Excited Dielectric Resonator Antenna with Parasitic Strips for Radiation Pattern Reconfigurability
}

\author{
M. Kamran Saleem, Majeed A. S. Alkanhal, and Abdel Fattah Sheta \\ Department of Electrical Engineering, King Saud University, P.O. Box 800, Riyadh 11421, Saudi Arabia \\ Correspondence should be addressed to M. Kamran Saleem; msaleem@ksu.edu.sa
}

Received 15 September 2013; Accepted 27 November 2013; Published 27 January 2014

Academic Editor: Zhaobiao Lv

Copyright ( 2014 M. Kamran Saleem et al. This is an open access article distributed under the Creative Commons Attribution License, which permits unrestricted use, distribution, and reproduction in any medium, provided the original work is properly cited.

\begin{abstract}
A novel pattern reconfigurable antenna concept utilizing rectangular dielectric resonator antenna (DRA) placed over dielectric substrate backed by a ground plane is presented. A dual strip excitation scheme is utilized and both excitation strips are connected together by means of a $50 \Omega$ microstrip feed network placed over the substrate. The four vertical metallic parasitic strips are placed at corner of DRA each having a corresponding ground pad to provide a short/open circuit between the parasitic strip and antenna ground plane, through which a shift of $90^{\circ}$ in antenna radiation pattern in elevation plane is achieved. A fractional bandwidth of approximately $40 \%$ at center frequency of $1.6 \mathrm{GHz}$ is achieved. The DRA peak realized gain in whole frequency band of operation is found to be above $4 \mathrm{~dB}$. The antenna configuration along with simulation and measured results are presented.
\end{abstract}

\section{Introduction}

The reconfigurable antennas are considered to be most appropriate candidates for increasing the functionality of wireless communications systems. A system performance can be enhanced by shifting the antenna main beam while maintaining the beam shape, operating frequency, and bandwidth. By utilizing an antenna with reconfigurable radiation patterns, mitigation in the interfering signals and improvement in the desired signal can be attained for enhancement in the wireless communication system. Several designs related to the pattern reconfigurable antenna elements based on metallic patch antenna technology have been proposed and studied [1-7]. These proposed designs exhibit many problems such as large in size, lossy, narrow bandwidth and have low radiation efficiency because of existence of metallic patches. The solution to these problems is to replace the metal patches with a low loss high permittivity dielectric resonator (DR) [8].

The dielectric resonator antenna (DRA) was first introduced by Long et al. in 1983 [9]. The DRA has many advantages such as small size, light weight, design flexibility, low dissipation loss, high radiation efficiency, and ease of excitation as well as wider impedance bandwidth as compared to metallic patch antennas $[10,11]$. Different shapes of DRAs such as rectangular, cylindrical, hemispherical, elliptical, pyramidal, and triangular along with various excitation schemes to couple energy into the DR element have been presented in the literature [11-17]. To the authors best knowledge to date, only a few pattern-reconfigurable antennas based on Dielectric Resonator (DR) are reported, where large square ground plane having size of approximately $2 \lambda_{0} \times 2 \lambda_{0}$ [18] and a circular ground plane having diameter of $3.5 \lambda_{0}[19]$ are presented. Furthermore, in reported articles, multiple coaxial probes are utilized and antenna radiation pattern is reconfigured by exciting one probe at a time while terminating the remaining with matched loads. In our proposed antenna structure, a single coaxial probe is utilized and antenna radiation pattern is reconfigured by electronic switching scheme. Furthermore, antenna ground plane size is significantly reduced having dimensions of $0.7 \lambda_{0} \times 0.7 \lambda_{0}$.

In this paper, we introduce a novel concept to achieve electronic reconfigurability in radiation pattern of a rectangular dielectric resonator antenna. We will show that with a dual strip excitation scheme along with parasitic strips each having a short/open circuit connection to antenna ground plane can be efficiently utilized to shift antenna radiation pattern at $90^{\circ}$ in elevation plane. RF PIN diode switches can be applied on the proposed antenna structure for switching 


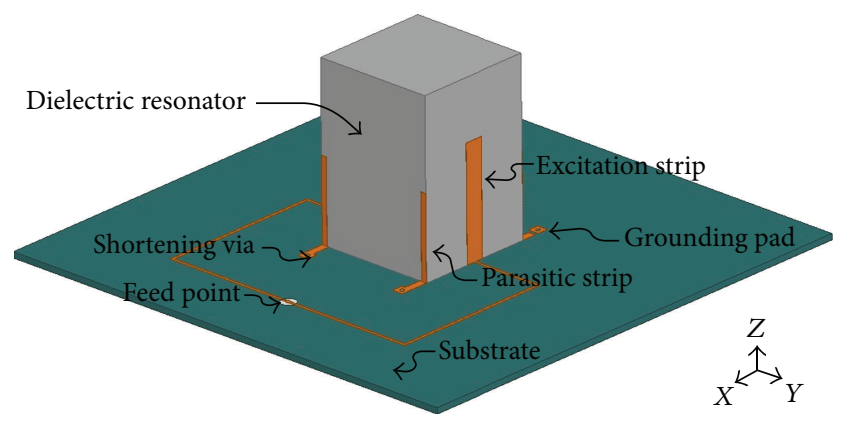

FIGURE 1: 3D model of proposed DRA structure.

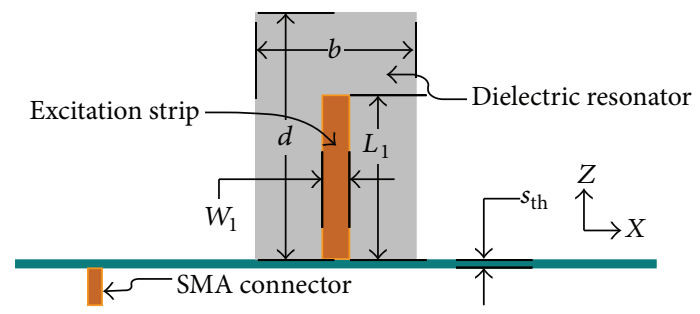

FIgURE 2: Proposed DRA structure ( $X Z$ plane).

action [20]. Furthermore, the resonance from parasitic strips and the $\mathrm{TE}_{111}$ mode of DRA are merged together to achieve wide impedance bandwidth. The organization of the paper is as follows. Antenna design and configuration along with importance of dual strip excitation scheme and parasitic strips are presented in Section 2. In Section 3 simulation results are presented. In Section 4, DRA fabrication along with a comparison between simulation and measured results is given. Finally conclusion and future work to enhance the proposed antenna results are given in Section 5.

\section{Proposed Antenna Design and Configuration}

2.1. Antenna Design and Configuration. The 3D model of proposed DRA is illustrated in Figure 1. The rectangular DRA has dimensions $a, b$, and $d$ and dielectric constant $\varepsilon_{r}$. The vertical metallic strip excitation method is chosen to excite the DR due to the ease of implementation, better energy coupling, convenient postmanufacturing trimming, and easy integration with the feed network on the substrate [21]. The two excitation strips are placed in the middle of the DRA side walls in $X Z$ plane having lengths $L_{1}$ and $W_{1}$ as shown in Figure 2.

Furthermore, as illustrated in Figure 3 four parasitic strips are placed at each corner of DRA face in $Y Z$ plane having length $L_{2}$ and width $W_{2}$. The top view of the antenna structure is illustrated in Figure 4, and the excitation strips are joined together by means of $50 \Omega$ microstrip lines over the substrate. The coaxial probe is located at a distance of $d_{\text {sma }}$ from the center of DRA. The four square-shaped grounding pads having dimensions $P_{W} \times P_{l}$ are placed on substrate at a distance of $P_{d}$ from the each parasitic strip a via hole of radius $V_{\text {rad }}$ through the substrate is made in each grounding

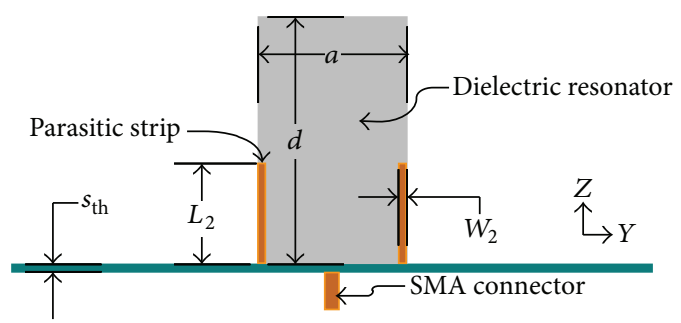

FIgURE 3: Proposed DRA structure ( $Y Z$ plane).

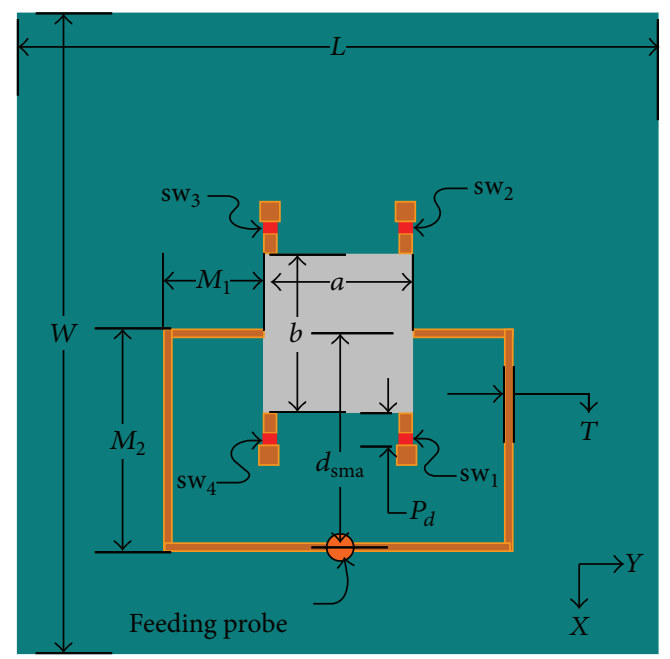

FIgURE 4: Top view of proposed antenna geometry (XY plane).

pad. The four switch locations are also illustrated in Figure 4, where $\mathrm{sw}_{1}, \mathrm{sw}_{2}, \mathrm{sw}_{3}$ and $\mathrm{sw}_{4}$ are used to provide a short/open circuit between the corresponding parasitic strip and antenna ground plane. The dimension of substrate backed by a ground plane is $130 \times 130 \mathrm{~mm}^{2}\left(\sim 0.7 \lambda_{0} \times 0.7 \lambda_{0}\right.$, where $\lambda_{0}$ is the free-space wavelength at $1.6 \mathrm{GHz}$ ) having thickness of $s_{\text {th }}=1.575 \mathrm{~mm}$ and dielectric constant that is $\varepsilon_{r}=4.4$.

Typically, in DRAs impedance bandwidth decreases with the increase in dielectric constant and width/height aspect ratio. Furthermore, the height of DR is used to control the frequency distance between the resonating modes; that is, by increasing the height of the DR the resonating modes can be brought close to each other [22, 23]. In our proposed DRA to achieve wider impedance bandwidth the dielectric constant of DR and $b / d$ aspect ratio is chosen to be 10 and 0.65 , respectively. Utilizing the dielectric waveguide model (DWM), the $\mathrm{TE}_{m n l}$ resonance frequency $\left(f_{0}\right)$ for rectangular DR can be calculated as follows [24]:

$$
\begin{gathered}
f_{0}=\frac{c}{2 \pi \sqrt{\varepsilon_{r}}} \sqrt{k_{x}^{2}+k_{y}^{2}+k_{z}^{2}}, \\
k_{x}=\frac{m \pi}{a}, \quad k_{z}=\frac{l \pi}{2 d}, \\
k_{y} \tan \left(\frac{k_{y} b}{2}\right)=\sqrt{\left(\varepsilon_{r}-1\right) k_{0}^{2}-k_{y}^{2}}, \quad(n=1), \\
k_{x}^{2}+k_{y}^{2}+k_{z}^{2}=\varepsilon_{r} k_{0}^{2},
\end{gathered}
$$




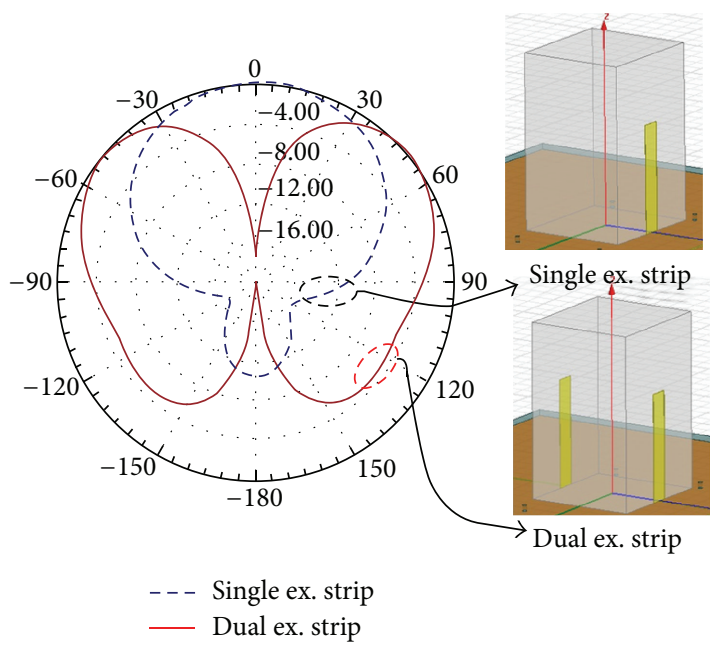

FIGURE 5: DRA 2D radiation pattern with single and dual strip excitation strips, without parasitic strips at $1.6 \mathrm{GHz}, a=32 \mathrm{~mm}$, $b=29.6 \mathrm{~mm}, d=48.85 \mathrm{~mm}, L_{1}=31.2 \mathrm{~mm}, W_{1}=5 \mathrm{~mm}$, and $M_{1}=25 \mathrm{~mm}$ and $M_{2}=45 \mathrm{~mm}, T=3 \mathrm{~mm}, s_{\text {th }}=1.575 \mathrm{~mm}$, $P_{d}=5 \mathrm{~mm}$, and $L=W=130 \mathrm{~mm}$.

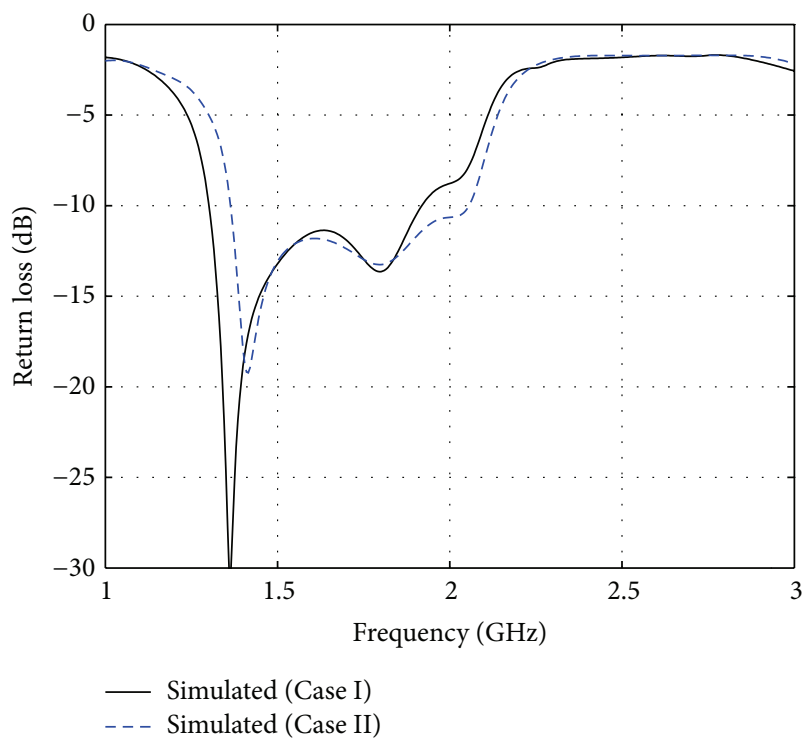

FIgURE 6: DRA return loss for both cases (Case I and Case II, as mentioned in Table 1), with $a=32 \mathrm{~mm}, b=29.6 \mathrm{~mm}, d=$ $48.85 \mathrm{~mm}, L_{1}=30 \mathrm{~mm}, W_{1}=5.3 \mathrm{~mm}, L_{2}=22 \mathrm{~mm}, W_{2}=1.5 \mathrm{~mm}$, and $M_{1}=20 \mathrm{~mm}$ and $M_{2}=45 \mathrm{~mm}, T=2.95 \mathrm{~mm}, d_{\text {sma }}=$ $44.26 \mathrm{~mm}, s_{\text {th }}=1.575 \mathrm{~mm}, P_{d}=5 \mathrm{~mm}$, and $L=W=130 \mathrm{~mm}$.

where $k_{0}$ is the free space wavenumber, $c$ is the speed of light in vacuum, and $k_{x}, k_{y}$, and $k_{z}$ are the wave number inside the DR in three directions. The subscripts $m, n$, and $l$ of $\mathrm{TE}_{m n l}$ denote the number of extremes in the $x, y$, and $z$ directions, respectively.

For $L$ band applications utilizing the above mentioned transcendental equations, the dimensions of dielectric resonator having $\varepsilon_{r}=10$ are found to be $a=29.6 \mathrm{~mm}, b=$ $32 \mathrm{~mm}$, and $d=48.85 \mathrm{~mm}$, resulting in dominant $\mathrm{TE}_{111}$ and higher order $\mathrm{TE}_{112}$ mode at 1.85 and $2.05 \mathrm{GHz}$, respectively.
TABLE 1: Switch configuration for antenna beam steering.

\begin{tabular}{lcccc}
\hline & \multicolumn{4}{c}{ Switches corresponding to each parasitic patch } \\
& Switch I & Switch II & Switch III & Switch IV \\
\hline Case I & on & off & off & on \\
Case II & off & on & on & off \\
\hline
\end{tabular}

2.2. Dual Strip for DR Excitation. The DRAs excited by a single point feed usually have a broad side radiation pattern, that is, having a maxima in broadside direction [18, 24, 25]. In our proposed antenna structure, we present a dual strip excitation scheme where excitation strips are placed at two opposite faces of DR and connected together by means of a $50 \Omega$ line. Through this excitation method, we can achieve a radiation pattern having a null in broadside direction with two main lobes having radiation maxima at approximately $\pm 45^{\circ}$ in elevation plane. A comparison of antenna radiation pattern with dual and single excitation strip is shown in Figure 5. The initial width and length of excitation strip are kept at $W_{1}=5 \mathrm{~mm}$ and $L_{1}=\lambda_{g} / 2=31.2 \mathrm{~mm}$ (where $\lambda_{g}=\lambda_{0} / \sqrt{\left(\varepsilon_{r}+1\right) / 2}$ and $\lambda_{0}$ is the free space wavelength at $2.05 \mathrm{GHz})$, respectively.

2.3. Parasitic Strips for Beam Steering. Next we place four parasitic strips having length $L_{2}=48.85$ and $W_{2}=1 \mathrm{~mm}$ at the corner of DR side wall in $Y Z$ plane. Note that initially the length of parasitic strip is kept equal to the height of DR. A connection between the parasitic strip and antenna ground plan is provided by means of a metallic via hole which is placed in grounding pads as shown in Figure 4. It is found that by providing a short circuit between the parasitic strips and antenna ground plane using corresponding switches $\mathrm{sw}_{1}$ and $\mathrm{sw}_{4}$, the antenna radiation in regime of positive $x$ axis direction can be suppressed, resulting in antenna main radiation beam to be at $\theta=-45^{\circ}$ in elevation plane. Similarly, using $\mathrm{sw}_{2}$ and $\mathrm{sw}_{3}$ to provide a short circuit between the parasitic strip and antenna ground plane antenna radiation in negative $x$-axis direction can be suppressed, resulting in antenna main radiation beam to be at $\theta=45^{\circ}$ in elevation plane. The switching configuration to achieve a $90^{\circ}$ shift in the direction of antenna maximum radiation is shown in Table 1. where, ON state refers to a short circuit between the corresponding parasitic strip and antenna ground plane and OFF state refers to open circuit between the corresponding parasitic strip and antenna ground plane.

\section{Simulation and Optimization}

The antenna presented in previous section is simulated and optimized using Ansys high frequency structure simulator (HFSS). The antenna structure is enclosed in a radiation boundary placed at $\lambda_{0} / 2$ (where $\lambda_{0}$ is free space wave length at $1.6 \mathrm{GHz}$ ) distance away from the antenna structure. The lumped RLC boundary conditions are used to model the switches in the simulation, where the resistance value of 0.001 Kohm and $3 \mathrm{Kohm}$ refers to ON and OFF state, respectively. The simulations are carried out with solution frequency set to 


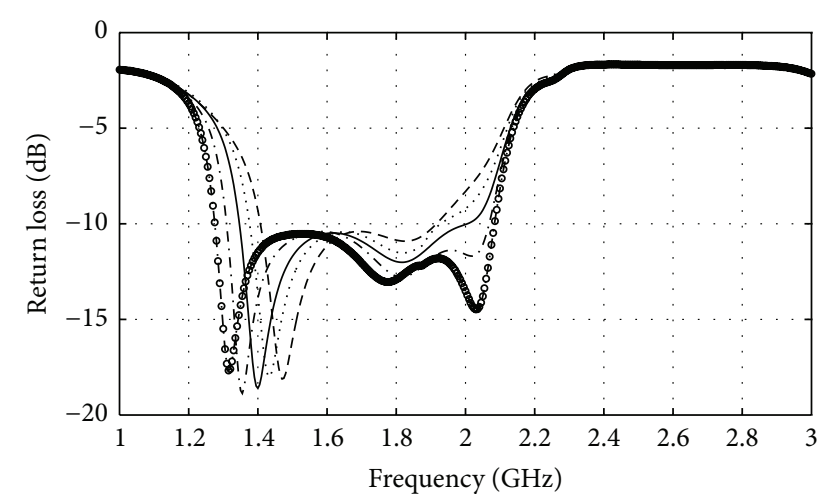

$$
\begin{aligned}
--L_{2}=19.5 \mathrm{~mm} & -.-L_{2}=22.5 \mathrm{~mm} \\
\ldots . . L_{2}=20.5 \mathrm{~mm} & -\circ-L_{2}=23.5 \mathrm{~mm} \\
-L_{2}=21.5 \mathrm{~mm} &
\end{aligned}
$$

FIGURE 7: Effect of parasitic strip height on DRA impedance bandwidth (Case I, as mentioned in Table 1), with $a=32 \mathrm{~mm}$, $b=29.6 \mathrm{~mm}, d=48.85 \mathrm{~mm}, L_{1}=30 \mathrm{~mm}, W_{1}=5.3 \mathrm{~mm}$, $W_{2}=1.5 \mathrm{~mm}$, and $M_{1}=20 \mathrm{~mm}$ and $M_{2}=45 \mathrm{~mm}, T=2.95 \mathrm{~mm}$, $d_{\mathrm{sma}}=44.26 \mathrm{~mm}, s_{\mathrm{th}}=1.575 \mathrm{~mm}, P_{d}=5 \mathrm{~mm}$, and $L=W=$ $130 \mathrm{~mm}$.

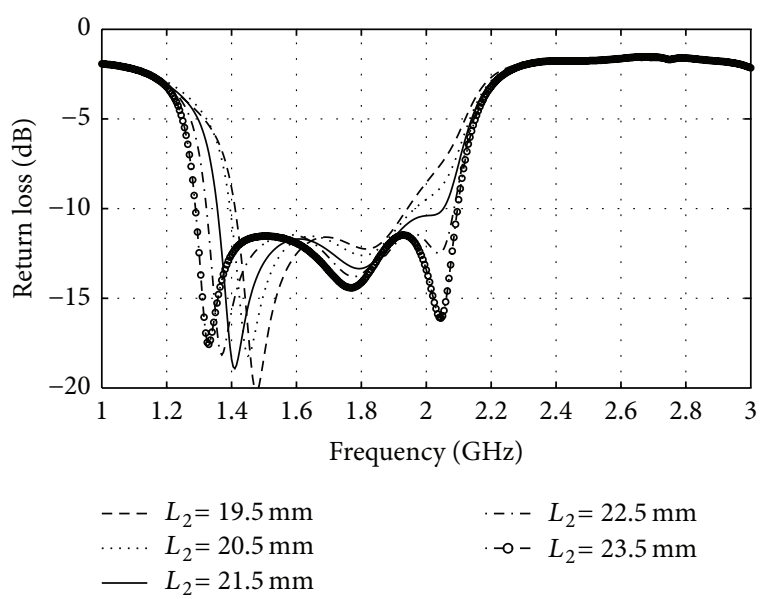

FIGURE 8: Effect of parasitic strip height on DRA impedance bandwidth (Case II, as mentioned in Table 1), with $a=32 \mathrm{~mm}$, $b=29.6 \mathrm{~mm}, d=48.85 \mathrm{~mm}, L_{1}=30 \mathrm{~mm}, W_{1}=5.3 \mathrm{~mm}$, $W_{2}=1.5 \mathrm{~mm}$, and $M_{1}=20 \mathrm{~mm}$ and $M_{2}=45 \mathrm{~mm}, T=2.95 \mathrm{~mm}$, $d_{\text {sma }}=44.26 \mathrm{~mm}, s_{\text {th }}=1.575 \mathrm{~mm}, P_{d}=5 \mathrm{~mm}$, and $L=W=$ $130 \mathrm{~mm}$.

1.6 $\mathrm{GHz}$ and fast sweep option is used with 701 points and $\Delta s$ is kept at 0.02 , while number of passes is set to 15 to meet the convergence criteria.

The antenna structure having dual excitation strips and four parasitic strips is optimized to achieve maximum impedance bandwidth and similar radiation patterns for both cases mentioned in Table 1. The initial dimensions are as follows: $a=32 \mathrm{~mm}, b=29.5 \mathrm{~mm}, d=48.85 \mathrm{~mm}, L_{1}=$ $31.2 \mathrm{~mm}, W_{1}=5 \mathrm{~mm}, L_{2}=48.85 \mathrm{~mm}, W_{2}=1 \mathrm{~mm}, M_{1}=$ $25 \mathrm{~mm}, M_{2}=45 \mathrm{~mm}, s_{\text {th }}=1.575 \mathrm{~mm}, V_{\mathrm{rad}}=0.6 \mathrm{~mm}$, $L=130 \mathrm{~mm}$, and $W=130 \mathrm{~mm}$.

We studied the antenna radiation pattern in whole frequency band of operation, and we found that the antenna

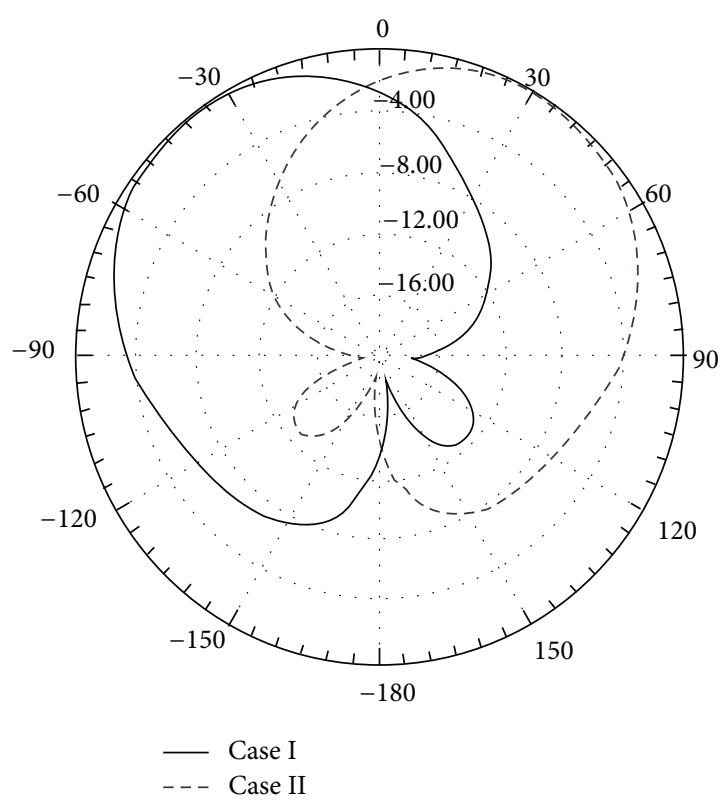

FIGURE 9: 2D radiation pattern for both cases mentioned in Table 1, with $a=32 \mathrm{~mm}, b=29.6 \mathrm{~mm}, d=48.85 \mathrm{~mm}, L_{1}=30 \mathrm{~mm}, W_{1}=$ $5.3 \mathrm{~mm}, L_{2}=22 \mathrm{~mm}, W_{2}=1.5 \mathrm{~mm}$, and $M_{1}=20 \mathrm{~mm}$ and $M_{2}=$ $45 \mathrm{~mm}, T=2.95 \mathrm{~mm}, d_{\mathrm{sma}}=44.26 \mathrm{~mm}, s_{\mathrm{th}}=1.575 \mathrm{~mm}, P_{d}=$ $5 \mathrm{~mm}$, and $L=W=130 \mathrm{~mm}$ at $1.6 \mathrm{GHz}$. The cross-polar values are too small to be visible in the above scale.

radiation pattern highly deviates in regime of higher order $\mathrm{TE}_{112}$ mode. A tedious optimization process is carried out in HFSS to get rid of $\mathrm{TE}_{112}$ mode, keeping in mind that this higher order mode that is $\mathrm{TE}_{112}$ is highly influenced by the length of excitation strip and can be disposed off by keeping the length of excitation strip below $\lambda_{g} / 2$ (where $\lambda_{g}$ is the guided wave length in DR) [25]. It is also observed that by keeping the length of parasitic strip below the half of the height of DR, we can significantly suppress the antenna radiation in unwanted direction. Thus, length of parasitic strip is kept below $d / 2$, that is, $L_{2}=24 \mathrm{~mm}$ (where $d$ is the height of DR). Furthermore, the feed network consists of $50 \Omega$ microstrip line placed in close proximity of DR over the substrate. We know that these microstrip lines can be used to couple energy to DR directly [26]. This feed network is also optimized to achieve acceptable return loss. Finally, antenna impedance bandwidth of approximately $600 \mathrm{MHz}(1.3-1.9 \mathrm{GHz})$ is achieved with similar radiation pattern characteristics throughout the whole frequency band of operation. The antenna return loss for the both cases mentioned in Table 1 is shown in Figure 6. The final optimized dimensions are as follows: $a=32 \mathrm{~mm}, b=29.5 \mathrm{~mm}, d=$ $48.85 \mathrm{~mm}, L_{1}=30 \mathrm{~mm}, W_{1}=5.3 \mathrm{~mm}, L_{2}=22 \mathrm{~mm}$, $W_{2}=1.5 \mathrm{~mm}$, and $M_{1}=20 \mathrm{~mm}$ and $M_{2}=45 \mathrm{~mm}, T=$ $2.95 \mathrm{~mm}, d_{\text {sma }}=44.26 \mathrm{~mm}, s_{\text {th }}=1.575 \mathrm{~mm}, P_{d}=5 \mathrm{~mm}$, and $L=W=130 \mathrm{~mm}$.

The parasitic strips height is optimized to achieve maximum impedance bandwidth with similar radiation pattern characteristics. The resonance from parasitic strip and $\mathrm{TE}_{111}$ mode of DRA are merged together to achieve wide 

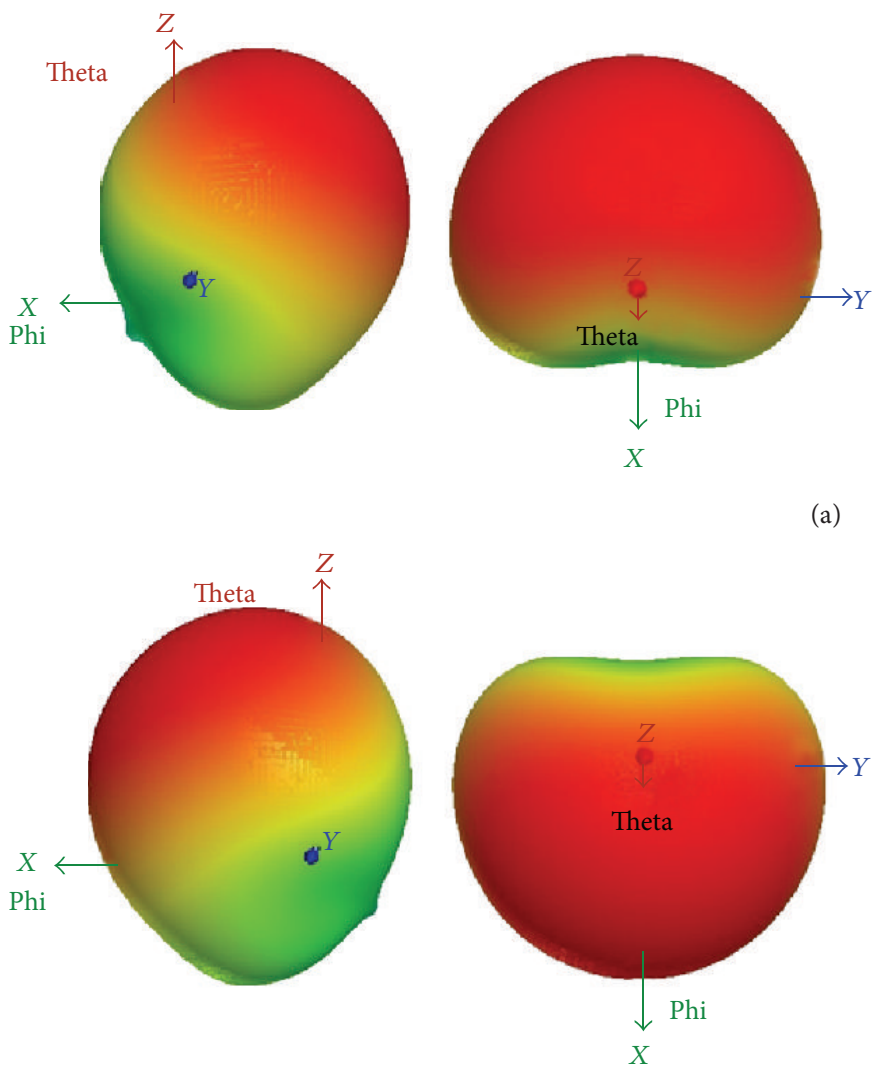

(a)

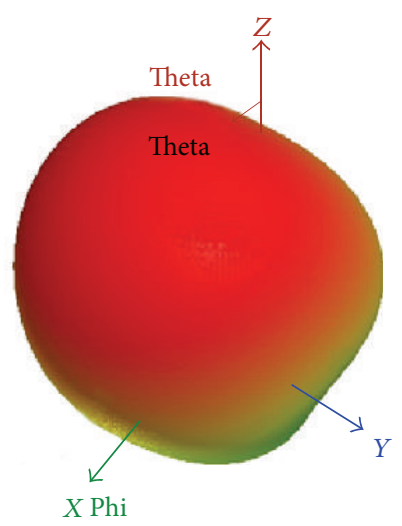

$4.5575 e+000$ $3.4188 e+000$ $2.2802 e+000$ $1.1415 e+000$ $2.8653 e-003$ $-1.1358 e+000$ $-2.2744 e+000$ $-3.4131 e+000$ $-4.5517 e+000.9$ $-5.6904 e+000$ ⿷匚 $-6.8290 e+000 \cong$ $-7.9677 e+000$ $-9.1063 e+000$ $-1.0245 e+001$ $-1.1384 e+001$ $-1.2522 e+001$ $-1.3661 e+001$

(b)

Figure 10: 3D radiation pattern for the both cases as mentioned in Table 1, with $a=32 \mathrm{~mm}, b=29.6 \mathrm{~mm}, d=48.85 \mathrm{~mm}, L_{1}=30 \mathrm{~mm}$, $W_{1}=5.3 \mathrm{~mm}, L_{2}=22 \mathrm{~mm}, W_{2}=1.5 \mathrm{~mm}$, and $M_{1}=20 \mathrm{~mm}$ and $M_{2}=45 \mathrm{~mm}, T=2.95 \mathrm{~mm}, d_{\text {sma }}=44.26 \mathrm{~mm}, s_{\text {th }}=1.575 \mathrm{~mm}, P_{d}=5 \mathrm{~mm}$, and $L=W=130 \mathrm{~mm}$. (a) Case I (1.6 GHz) and (b) Case II (1.6 GHz).

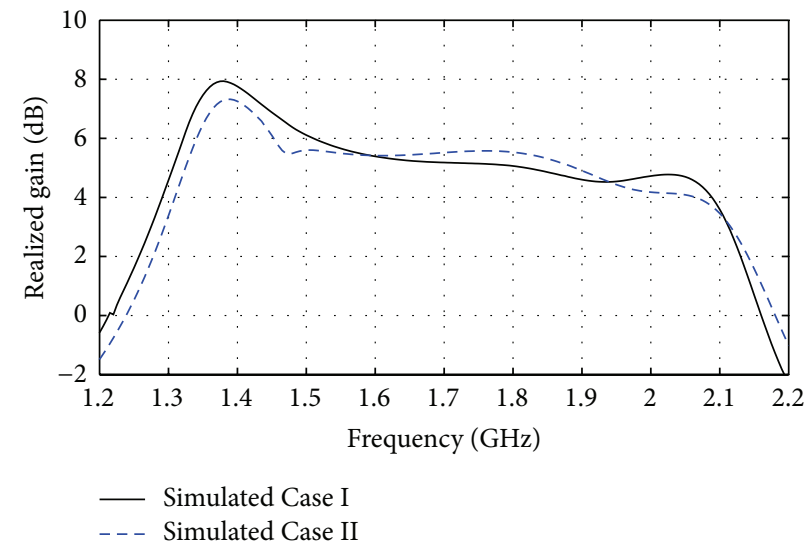

Figure 11: Realized antenna gain for both cases (Case I and Case II, as mentioned in Table 1), with $a=32 \mathrm{~mm}, b=29.6 \mathrm{~mm}, d=48.85 \mathrm{~mm}$, $L_{1}=30 \mathrm{~mm}, W_{1}=5.3 \mathrm{~mm}, L_{2}=22 \mathrm{~mm}, W_{2}=1.5 \mathrm{~mm}$, and $M_{1}=20 \mathrm{~mm}$ and $M_{2}=45 \mathrm{~mm}, T=2.95 \mathrm{~mm}, d_{\mathrm{sma}}=44.26 \mathrm{~mm}, s_{\mathrm{th}}=1.575 \mathrm{~mm}$, $P_{d}=5 \mathrm{~mm}$, and $L=W=130 \mathrm{~mm}$. 


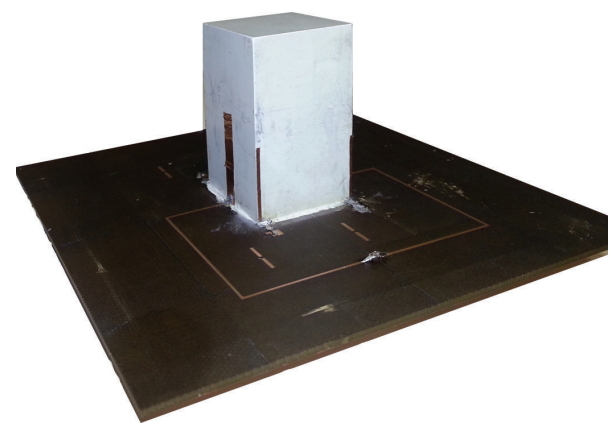

FIGURE 12: Manufactured prototype DRA with $a=32 \mathrm{~mm}, b=$ $29.5 \mathrm{~mm}, d=48.85 \mathrm{~mm}, \varepsilon_{r}=10, L_{1}=31 \mathrm{~mm}, W_{1}=5 \mathrm{~mm}, L_{2}=$ $21 \mathrm{~mm}, W_{2}=1.5 \mathrm{~mm}, M_{1}=22 \mathrm{~mm}, M_{2}=33 \mathrm{~mm}, s_{\text {th }}=1.575 \mathrm{~mm}$, $V_{\text {rad }}=0.6 \mathrm{~mm}, L=130 \mathrm{~mm}, P_{W}=P_{l}=2 \mathrm{~mm}$, and $W=130 \mathrm{~mm}$.

impedance bandwidth. The optimum height of parasitic strip is found to be $L_{2}=22 \mathrm{~mm}$ with similar radiation pattern characteristics throughout the whole frequency band of operation. The effect of change in parasitic strip height is shown in Figures 7 and 8 for Case I and Case II, respectively.

The $2 \mathrm{D}$ radiation pattern at center frequency of $1.6 \mathrm{GHz}$ for both mentioned cases is shown in Figure 9. The maximum value of antenna radiation beam is found to be at $\varphi=0^{\circ}$ and $\theta=-42^{\circ}$ for Case $\mathrm{I}$ and at $\varphi=0^{\circ}$ and $\theta=42^{\circ}$ for Case II having antenna beam width of $70^{\circ}$ for both cases. For a better visualization of beam steering in elevation plane, the antenna 3D radiation pattern is shown in Figure 10. The antenna radiation pattern is tilted towards the negative $x$ axis, when switches are configured as mentioned in Case I (i.e., $\mathrm{sw}_{1}=\mathrm{ON}, \mathrm{sw}_{2}=\mathrm{OFF}, \mathrm{sw}_{3}=\mathrm{OFF}$, and $\mathrm{sw}_{4}=\mathrm{ON}$ ) and tilled towards the positive $x$-axis when switches are configured as mentioned in Case II (i.e., $\mathrm{sw}_{1}=\mathrm{OFF}, \mathrm{sw}_{2}=\mathrm{ON}$, $\mathrm{sw}_{3}=\mathrm{ON}$, and $\left.\mathrm{sw}_{4}=\mathrm{OFF}\right)$. The antenna radiation patterns remain similar with maximum radiation direction changing smoothly from $40^{\circ}$ to $45^{\circ}$ as the frequency increases. The overall realized gain of DRA is found to be above $4 \mathrm{~dB}$ in the whole frequency band of operation $(1.3-1.9 \mathrm{GHz})$ for both cases mentioned in Table 1 and is illustrated in Figure 11.

\section{Antenna Fabrication and Measurements}

The prototype of proposed DRA is shown in Figure 12. The DR having $\varepsilon_{r}=10$ is fixed over the FR4 substrate with ecostock paste having $\varepsilon_{r}=10$. The excitation and parasitic strips with required dimensions are cut from adhesive tape and placed over the DR faces at appropriate positions. As mentioned earlier, the length of excitation strip is tuned to get rid of $\mathrm{TE}_{112}$ mode so that a similar radiation pattern can be attained throughout the whole frequency band of operation. The via holes are drilled in the substrate and filled with silver epoxy to provide a connection between grounding pads and antenna ground plane. The switches are hard-wired for the proof of concept and small pieces of copper wires are used to provide a short circuit between the parasitic strip and corresponding grounding pads, where each grounding pad is connected to antenna ground plane through a metallic via hole.

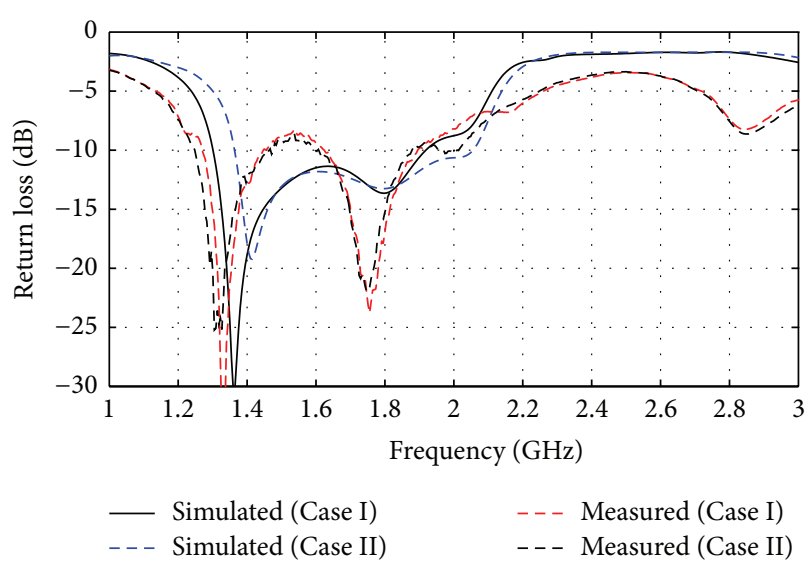

FIGURE 13: Comparison between measured and simulated antenna return loss with $a=32 \mathrm{~mm}, b=29.5 \mathrm{~mm}, d=48.85 \mathrm{~mm}, \varepsilon_{r}=10$, $L_{1}=31 \mathrm{~mm}, W_{1}=5 \mathrm{~mm}, L_{2}=21 \mathrm{~mm}, W_{2}=1.5 \mathrm{~mm}, M_{1}=$ $22 \mathrm{~mm}, M_{2}=33 \mathrm{~mm}, s_{\mathrm{th}}=1.575 \mathrm{~mm}, V_{\mathrm{rad}}=0.6 \mathrm{~mm}, P_{W}=P_{l}=$ $2 \mathrm{~mm}, L=130 \mathrm{~mm}$ and $W=130 \mathrm{~mm}$.

TABLE 2: Comparison of resonant frequencies.

\begin{tabular}{lccc}
\hline Resonant mode & Measured & (HFSS) & (DWM) \\
\hline & $f_{\text {mea }}(\mathrm{GHz})$ & $f_{\text {HFss }}(\mathrm{GHz})$ & $f_{\mathrm{DWM}}(\mathrm{GHz})$ \\
$\mathrm{TE}_{111}$ & 1.79 & 1.8 & 1.82 \\
\hline
\end{tabular}

The antenna return loss for the both cases is measured using the network analyzer and is compared with the simulated return loss as shown in Figure 13. The dominant $\mathrm{TE}_{111}$ mode is found at approximately $1.79 \mathrm{GHz}$ giving impedance bandwidth of $650 \mathrm{MHz}(1.25-1.9 \mathrm{GHz})$ at center frequency of $1.6 \mathrm{GHz}$ with similar radiation pattern in whole frequency band of operation. A good agreement between the measured, simulated, and predicted (DWM) resonance frequencies is found. The comparison between the theory, simulation, and measured resonance frequencies is shown in Table 2. The difference of impedance bandwidth between measured and simulated results due to fabrication accuracy is found to be approximately $50 \mathrm{MHz}$. The antenna radiation pattern is measured using the GEOZONDAS time domain measurement setup, and a very reasonable agreement between the simulated and measured results is obtained. The comparison of measured and simulated radiation patterns at 1.3, 1.55, and $1.75 \mathrm{GHz}$ for Case I and Case II mentioned in Table 1 is shown in Figures 14 and 15, respectively.

\section{Conclusion}

A dielectric resonator antenna with reconfigurable radiation pattern is presented. The DRA consists of rectangular DR with two excitation and four parasitic strips. The DR is mounted over FR4 substrate backed by a ground plane. The DWM theory is utilized to find the appropriate dimensions of $\mathrm{DR}$ and dominant $\mathrm{TE}_{111}$ mode is generated. It is shown that by utilizing a simple switching scheme for a short/open circuit between the parasitic strips and antenna ground plane the antenna main beam can be reconfigured to an angle 


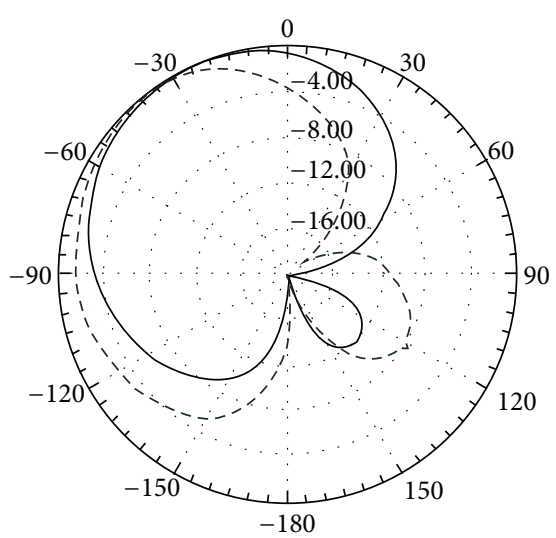

(a)

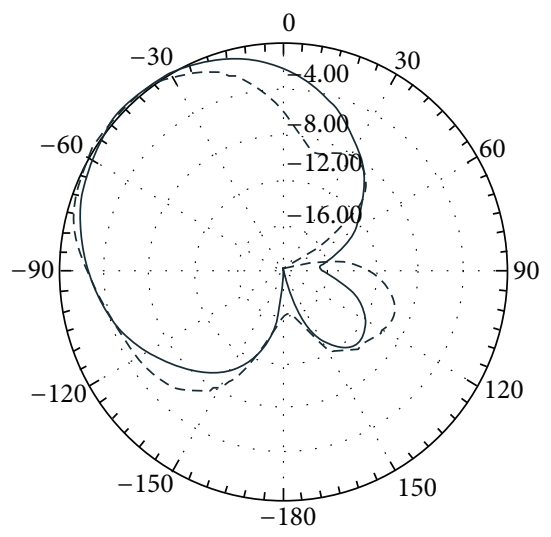

(b)

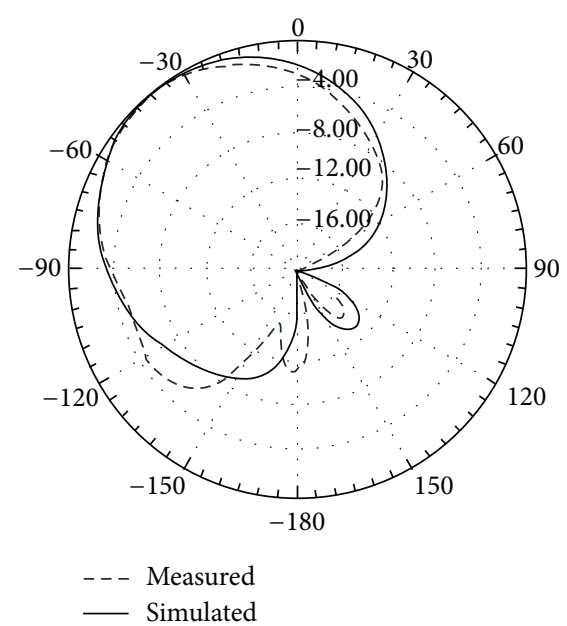

(c)

FIGURE 14: Simulated and measured 2D radiation patterns for Case I, with $a=32 \mathrm{~mm}, b=29.5 \mathrm{~mm}, d=48.85 \mathrm{~mm}, \varepsilon_{r}=10, L_{1}=$ $31 \mathrm{~mm}, W_{1}=5 \mathrm{~mm}, L_{2}=21 \mathrm{~mm}, W_{2}=1.5 \mathrm{~mm}, M_{1}=22 \mathrm{~mm}$, $M_{2}=33 \mathrm{~mm}, s_{\text {th }}=1.575 \mathrm{~mm}, V_{\text {rad }}=0.6 \mathrm{~mm}, P_{W}=P_{l}=2 \mathrm{~mm}, L=$ $130 \mathrm{~mm}$, and $W=130 \mathrm{~mm}$. (a) $1.3 \mathrm{GHz}$ (b) $1.55 \mathrm{GHz}$ (c) $1.75 \mathrm{GHz}$. The cross-polar values are too small to be visible in the above scale.

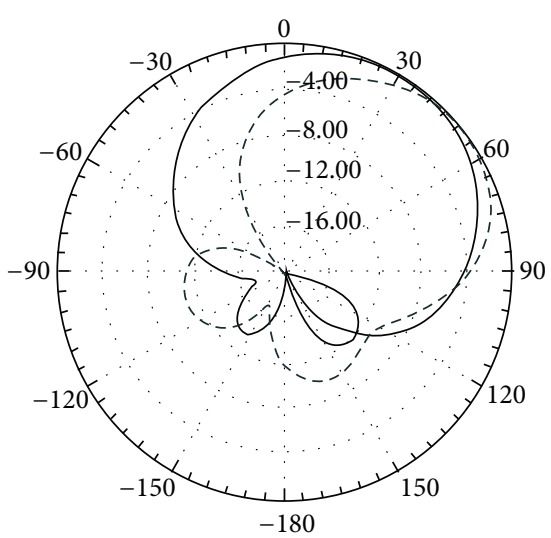

(a)

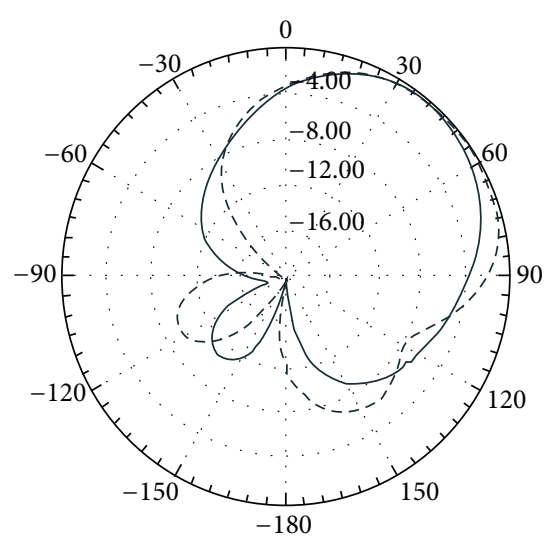

(b)

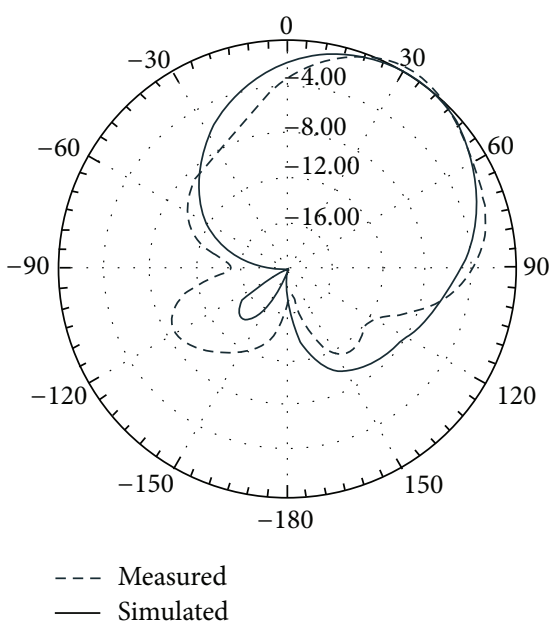

(c)

Figure 15: Simulated and measured 2D radiation patterns for Case II, with $a=32 \mathrm{~mm}, b=29.5 \mathrm{~mm}, d=48.85 \mathrm{~mm}, \varepsilon_{r}=10, L_{1}=$ $31 \mathrm{~mm}, W_{1}=5 \mathrm{~mm}, L_{2}=21 \mathrm{~mm}, W_{2}=1.5 \mathrm{~mm}, M_{1}=22 \mathrm{~mm}$, $M_{2}=33 \mathrm{~mm}, s_{\text {th }}=1.575 \mathrm{~mm}, V_{\text {rad }}=0.6 \mathrm{~mm}, P_{W}=P_{l}=2 \mathrm{~mm}, L=$ $130 \mathrm{~mm}$ and $W=130 \mathrm{~mm}$. (a) $1.3 \mathrm{GHz}$ (b) $1.55 \mathrm{GHz}$ (c) $1.75 \mathrm{GHz}$. The cross-polar values are too small to be visible in the above scale. 
of $90^{\circ}$ in elevation plane maintaining the similar radiation characteristics as well as impedance bandwidth of $650 \mathrm{MHz}$ (1.25-1.9 GHz).

The proposed antenna is expected to be more efficient than that microstrip patch antenna, especially at millimeter wave frequencies where skin effect is strong. Furthermore, the proposed antenna structure is a potential candidate for the enhancement in array systems to achieve beam steering in azimuth/elevation plane with a wider impedance bandwidth. Effects of physical parameters such as dielectric substrate, excitation strips, parasitic strips, and ground plane will be further studied to improve the radiation pattern reconfigurability. The implementation of RF PIN diodes in proposed antenna structure is underway.

\section{Conflict of Interests}

The authors declare that there is no conflict of interests regarding the publication of this paper.

\section{Acknowledgment}

This research work is supported by the National Plan for Science and Technology (NPST), Kingdom of Saudi Arabia, under project no. 10-ELE996-02.

\section{References}

[1] A. C. K. Mak, C. R. Rowell, and R. D. Murch, "Low cost reconfigurable landstorfer planar antenna array," IEEE Transactions on Antennas and Propagation, vol. 57, no. 10, pp. 3051-3061, 2009.

[2] X. Cai, A. Wang, N. Ma, and W. Leng, "A novel planar parasitic array antenna with reconfigurable azimuth pattern," IEEE Antennas and Wireless Propagation Letters, vol. 11, pp. 1186-1189, 2012.

[3] L. Nan and A.-G. Wang, "A novel tree-shaped antenna with reconfigurable radiation pattern," in Proceedings of the AsiaPacific Symposium on Electromagnetic Compatibility (APEMC '10), pp. 1333-1336, Beijing, China, April 2010.

[4] Y. Tawk, J. Costantine, S. Hemmady, G. Balakrishnan, K. Avery, and C. G. Christodoulou, "Demonstration of a cognitive radio front end using an optically pumped reconfigurable antenna system (OPRAS)," IEEE Transactions on Antennas and Propagation, vol. 60, no. 2, pp. 1075-1083, 2012.

[5] G. H. Huff and J. T. Bernhard, "Integration of packaged RF MEMS switches with radiation pattern reconfigurable square spiral microstrip antennas," IEEE Transactions on Antennas and Propagation, vol. 54, no. 2, pp. 464-469, 2006.

[6] W. H. Chen, J. W. Sun, X. Wang et al., "A novel planar switched parasitic array antenna with steered conical pattern," IEEE Transactions on Antennas and Propagation, vol. 55, no. 6, pp. 1883-1887, 2007.

[7] S. Zhang, G. H. Huff, J. Feng, and J. T. Bernhard, "A pattern reconfigurable microstrip parasitic array," IEEE Transactions on Antennas and Propagation, vol. 52, no. 10, pp. 2773-2776, 2004.

[8] A. A. Kishk, M. R. Zunoubi, and D. Kajfez, "Numerical study of a dielectric disk antenna above grounded dielectric substrate," IEEE Transactions on Antennas and Propagation, vol. 41, no. 6, pp. 813-821, 1993.
[9] S. A. Long, M. W. McAllister, and L. C. Shen, "The resonant cylindrical dielectric cavity antenna," IEEE Transactions on Antennas and Propagation, vol. 31, no. 3, pp. 406-412, 1983.

[10] I. A. Eshrah, A. A. Kishk, A. B. Yakovlev, and A. W. Glisson, "Theory and implementation of dielectric resonator antenna excited by a waveguide slot," IEEE Transactions on Antennas and Propagation, vol. 53, no. 1, pp. 483-494, 2005.

[11] A. Petosa and A. Ittipiboon, "Dielectric resonator antennas: a historical review and the current state of the art," IEEE Antennas and Propagation Magazine, vol. 52, no. 5, pp. 91-116, 2010.

[12] A. A. Kishk, "Tetrahedron and triangular dielectric resonator antenna with wideband performance," in Proceedings of the IEEE Antennas and Propagation Society International Symposium, vol. 4, pp. 462-465, June 2002.

[13] G. Zhou, A. A. Kishk, and A. W. Glisson, "Input impedance of a hemispherical dielectric resonator antenna excited by a coaxial probe," in Proceedings of the IEEE Antennas and Propagation Society International Symposium, vol. 2, pp. 1038-1041, July 1993.

[14] S. L. S. Yang, R. Chair, A. A. Kishk, K. F. Lee, and K. M. Luk, "Aperture feed elliptical dielectric resonator antenna for circularly polarized applications," in Proceedings of the 22nd Annual Review of Progress in Applied Computational Electromagnetics, pp. 94-100, Miami, Fla, USA, March 2006.

[15] S.-L. S. Yang, R. Chair, A. A. Kishk, K.-F. Lee, and K.-M. Luk, "Study on sequential feeding networks for subarrays of circularly polarized elliptical dielectric resonator antenna," IEEE Transactions on Antennas and Propagation, vol. 55, no. 2, pp. 321-333, 2007.

[16] S. L. S. Yang, R. Chair, A. A. Kishk, K. F. Lee, and K. M. Luk, "Single-feed elliptical dielectric resonator antennas for circularly polarized applications," Microwave and Optical Technology Letters, vol. 48, no. 11, pp. 2340-2345, 2006.

[17] A. Tadjalli, A. R. Sebak, T. A. Denidni, and A. A. Kishk, "Spheroidal dielectric resonator antenna," in Proceedings of the USNC/URSI National Radio Science Meeting (APSURSI '08), p. 184, July 2008.

[18] H. Fayad and P. Record, "Multi-feed dielectric resonator antenna with reconfigurable radiation pattern," Progress in Electromagnetics Research, vol. 76, pp. 341-356, 2007.

[19] M. Grag and S. K. Sharma, "Wide-bandwidth dielectric resonator antenna with omni-directional radiation patterns for beam focusing properties in a circular array," International Journal of RF and Microwave Computer-Aided Engineering, vol. 24, no. 1, pp. 92-101, 2014.

[20] A.-F. Sheta and S. F. Manmoua, "A widely tunable compact patch antenna," IEEE Antennas and Wireless Propagation Letters, vol. 7, pp. 40-42, 2008.

[21] K. W. Leung, "Conformai strip excitation of dielectric resonator antenna," IEEE Transactions on Antennas and Propagation, vol. 48, no. 6, pp. 961-967, 2000.

[22] A. Rashidian and D. M. Klymyshyn, "On the two segmented and high aspect ratio rectangular dielectric resonator antennas for bandwidth enhancement and miniaturization," IEEE Transactions on Antennas and Propagation, vol. 57, no. 9, pp. 27752780, 2009.

[23] C. S. de Young and S. A. Long, "Wideband cylindrical and rectangular dielectric resonator antennas," IEEE Antennas and Wireless Propagation Letters, vol. 5, no. 1, pp. 426-429, 2006.

[24] R. K. Mongia and A. Ittipiboon, "Theoretical and experimental investigations on rectangular dielectric resonator antennas," IEEE Transactions on Antennas and Propagation, vol. 45, no. 9, pp. 1348-1356, 1997. 
[25] B. Li and K. W. Leung, "Strip-fed rectangular dielectric resonator antennas with/without a parasitic patch," IEEE Transactions on Antennas and Propagation, vol. 53, no. 7, pp. 2200-2207, 2005.

[26] A. Petosa, Dielectric Resonator Antenna Handbook, Artech House, Norwood, Mass, USA, 2007. 

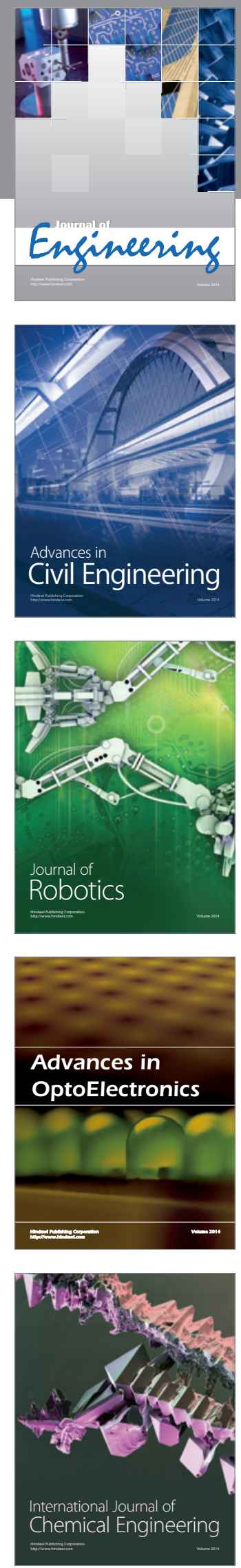

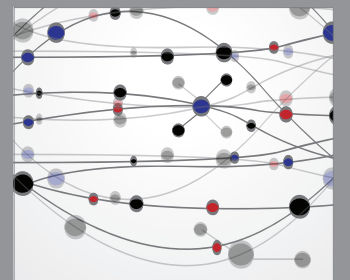

The Scientific World Journal
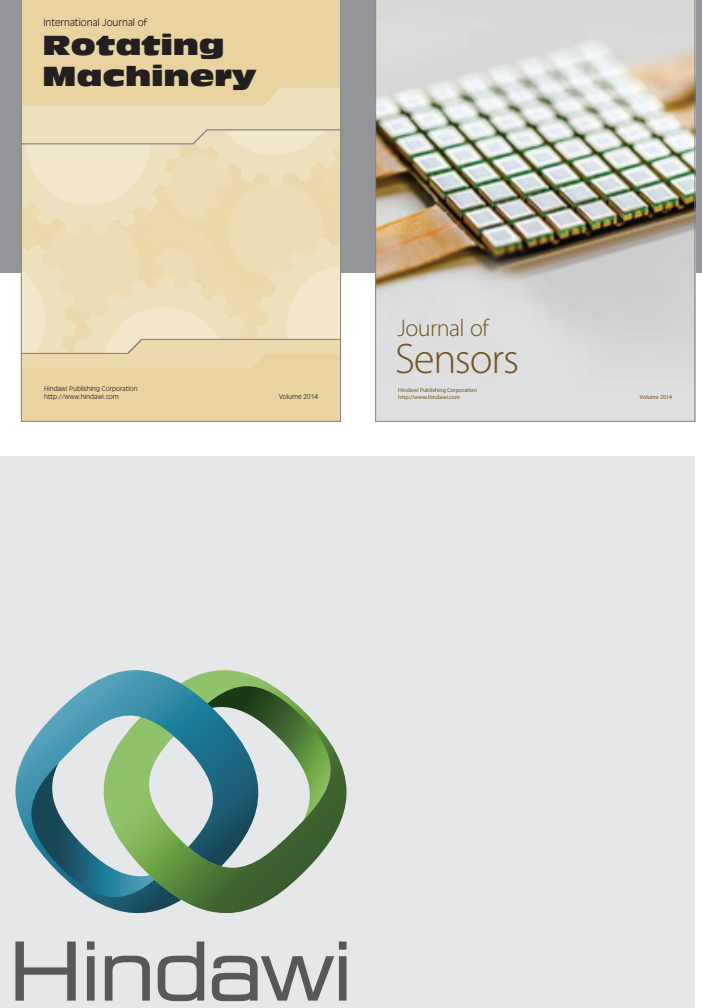

Submit your manuscripts at http://www.hindawi.com
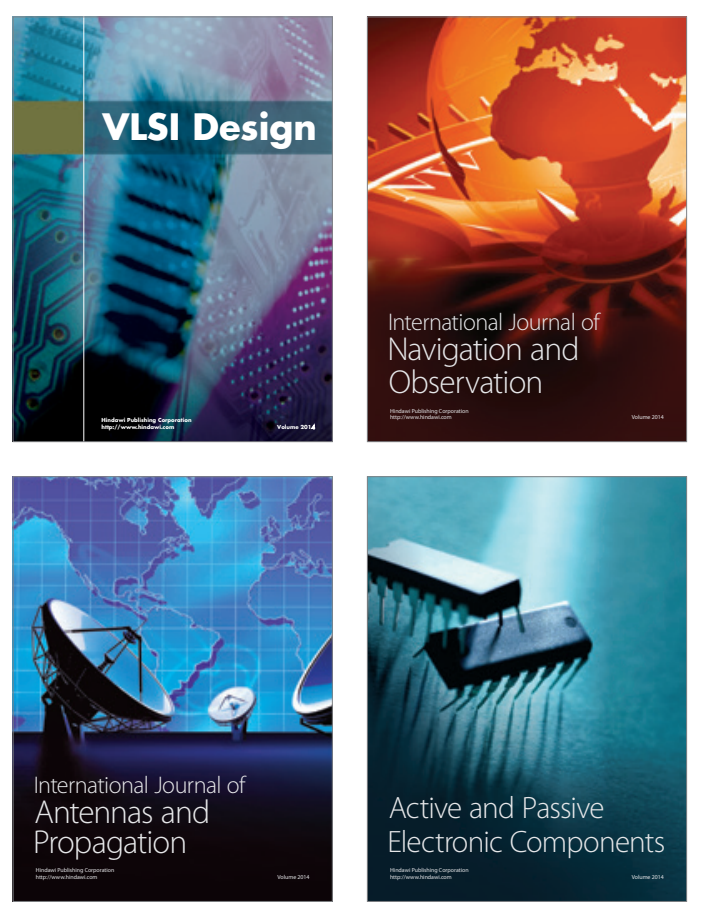
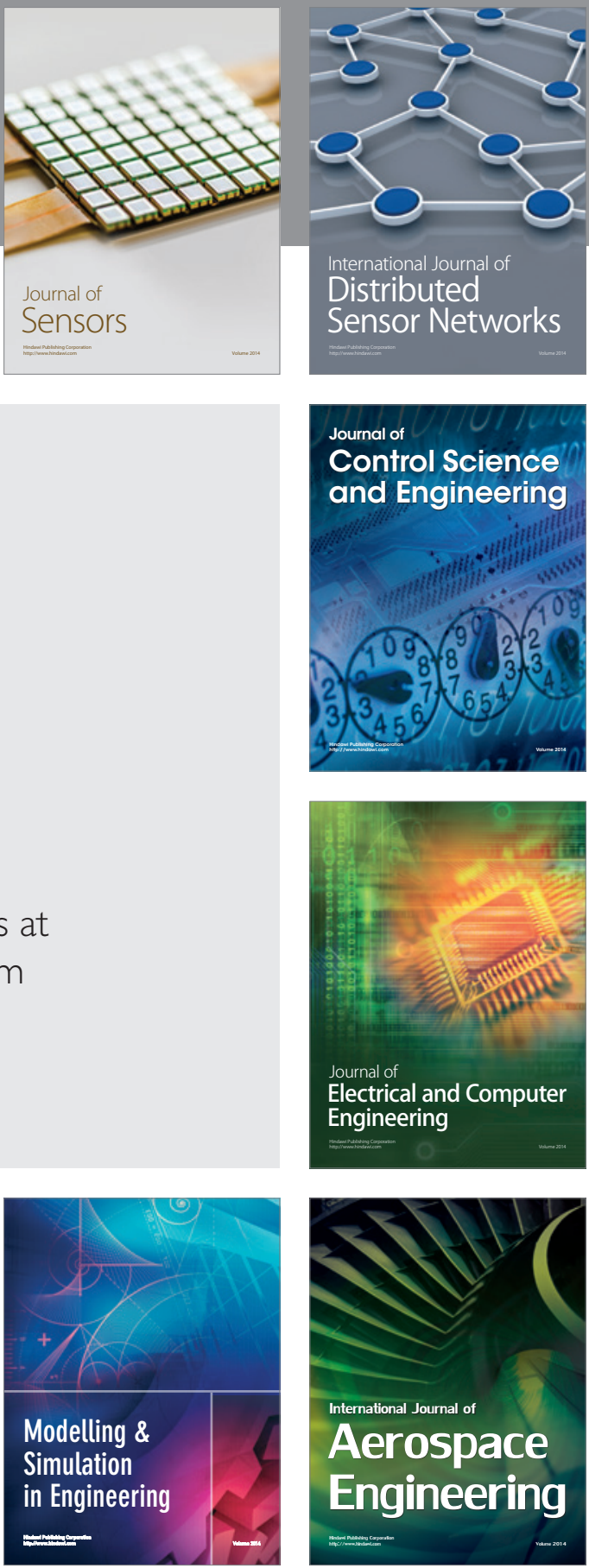

Journal of

Control Science

and Engineering
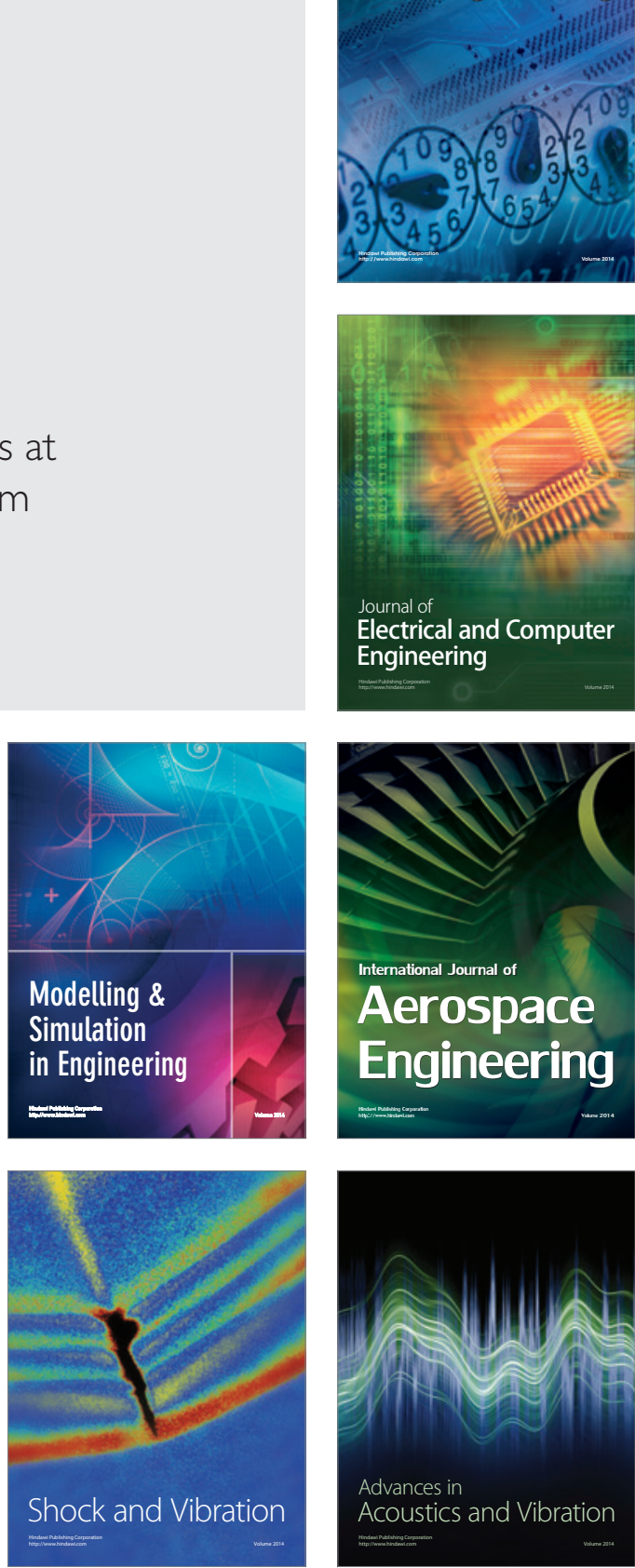